\section{Multiphoton Excitation in Molecular Bismuth}

Omar Babaky and Ari Topouzkhanian

Laboratoire de Spectrométrie Ionique et Moléculaire Université Claude Bernard (Lyon I), 69622 Villeurbanne Cedex (France)

Z. Naturforsch. 38 a, 1270-1272 (1983); received July 11, 1983

Two new molecular emissions have been observed at $400 \mathrm{~nm}$ and $250 \mathrm{~nm}$ in bismuth vapour after visible and infrared multiphoton absorption. A new state of even parity, labelled $W$ and lying at more than $37600 \mathrm{~cm}^{-1}$ from the ground state, has been evidenced. Known atomic lines are also excited via dissociation of repulsive states.

Reprint requests to Dr. A. Topouzkhanian, Laboratoire de Spectrométrie Ionique et Moléculaire, Université Lyon I, 43. Boulevard du 11 Novembre 1918,69622 Villeurbanne Cedex (France).
Diatomic bismuth has proved to be a very efficient medium for laser oscillations [1]. Accordingly extensive spectroscopic investigations have been carried out recently. utilizing continuous wave $\mathrm{Ar}^{+}$or $\mathrm{Kr}^{+}$lasers [2]. This paper reports the fluorescence of $\mathrm{Bi}_{2}$ induced by a pulsed laser emitting in the infrared, visible and ultraviolet by frequency doubling and tripling.

Bismuth vapour, contained in a cross-shaped heat pipe at $940^{\circ} \mathrm{C}$, has been excited by a YAG laser (pulse duration $\sim 11 \mathrm{~ns}$, linewidth $\sim 0.7 \mathrm{~cm}^{-1}$ at $1.064 \mu$, repetition rate: $10 \mathrm{~Hz}$ ). The fluorescence, observed perpendicular to the laser beam, has been recorded using a Boxcar averager. The input energy was $850 \mathrm{~mJ}$ for the fundamental infrared radiation $(1.064 \mu)$. Second and third harmonics were also utilized, pure or mixed $(350 \mathrm{~mJ}$ at $532 \mathrm{~nm}$ and $130 \mathrm{~mJ}$ at $355 \mathrm{~nm}$ ). Known single-photon laser-induced fluorescence series have been excited in the systems $\mathrm{A} \rightarrow \mathrm{X}$ and $\mathrm{V} \rightarrow \mathrm{X}$ respectively, when the visible and ultraviolet components were focused separately in the heat pipe [2]. Moreover, two new molecular emissions as well as atomic lines have been observed, due to multiphoton excitation.

Table 1. Atomic emission lines of bismuth via multiphoion absorption and dissociation.

\begin{tabular}{|c|c|c|c|c|c|c|c|c|}
\hline \multicolumn{2}{|l|}{ Excited level } & \multicolumn{2}{|l|}{ Emission line } & \multicolumn{5}{|c|}{ Relative intensity ${ }^{g}$} \\
\hline \multirow{2}{*}{$\begin{array}{l}\text { Configura- } \\
\text { tion }\end{array}$} & \multirow{2}{*}{$\begin{array}{l}\text { Energy }{ }^{a} \\
\left(\mathrm{~cm}^{-1}\right)\end{array}$} & \multirow[t]{2}{*}{ Transition } & \multirow{2}{*}{$\begin{array}{l}\text { Wavelength }{ }^{\mathrm{b}} \\
(\AA)\end{array}$} & \multicolumn{5}{|c|}{ Excitation } \\
\hline & & & & $\begin{array}{l}\text { Pure } \\
\text { IR }\end{array}$ & $\begin{array}{l}\text { Pure } \\
\text { Vis. }\end{array}$ & IR + Vis. & $\mathrm{IR}+\mathrm{UV}$ & $\mathrm{IR}+$ Vis. + UV \\
\hline $10 \leqslant\left\{\begin{array}{l}2 \mathrm{P}_{1 / 2} \\
4 \mathrm{P}_{3 / 2}\end{array}\right.$ & 67826.8 & $\left.\begin{array}{l}{ }^{2} \mathrm{P}_{1 / 2}-{ }^{2} \mathrm{P}_{3 / 2}^{0} \\
{ }^{4} \mathrm{P}_{3 / 2}\end{array}\right\}$ & $2883.81^{\mathrm{c}}$ & & & & $\mathrm{vw}$ & \\
\hline $7 d_{1 / 2}$ & 64236.9 & $7 \mathrm{~d}_{1 / 2}-{ }^{2} \mathrm{P}_{1 / 2}^{0}$ & 2347.89 & vw & & & & \\
\hline $8 \mathrm{~s}^{2} \mathrm{P}_{3 / 2}$ & 64020.8 & ${ }^{2} \mathrm{P}_{3 / 2}-{ }^{2} \mathrm{P}_{1 / 2}^{0}$ & $(2360.1)$ & & & & $\mathrm{vw}$ & \\
\hline $8 s{ }^{4} P_{3 / 2}$ & 60812.1 & ${ }^{4} \mathrm{P}_{3 / 2}-{ }^{2} \mathrm{D}_{5 / 2}^{0}$ & 2203.12 & vw & & & & \\
\hline $6 \mathrm{~d}_{5 / 2}$ & 58274.5 & $6 \mathrm{~d}_{5 / 2}-{ }^{2} \mathrm{D}_{3 / 2}^{0}$ & 2133.63 & $\mathrm{vw}$ & & & & \\
\hline $6 \mathrm{~d}_{1 / 2}$ & 57607.8 & $6 \mathrm{~d}_{1 / 2}-{ }^{2} \mathrm{P}_{1 / 2}^{0}$ & $2781.26^{\mathrm{d}}$ & & & & & w \\
\hline $10 \mathrm{~d}^{2} \mathrm{D}_{3 / 2}$ & 56329.8 & ${ }^{2} \mathrm{D}_{3 / 2}-{ }^{2} \mathrm{P}_{1 / 2}^{0}$ & $2883.81^{\mathrm{c}}$ & & & & $\mathrm{vw}$ & \\
\hline $9 \mathrm{~d}^{2} \mathrm{D}_{3 / 2}$ & 55424.7 & ${ }^{2} \mathrm{D}_{3 / 2}-{ }^{2} \mathrm{D}_{5 / 2}^{0}$ & 2499.51 & & & & $\mathrm{vw}$ & \\
\hline $7 \mathrm{~d}-\mathrm{D}_{3 / 2}$ & 51018.6 & ${ }^{2} \mathrm{D}_{3 / 2}-{ }^{2} \mathrm{P}_{1 / 2}^{0}$ & 3405.66 & & & w & & \\
\hline $7 \mathrm{~s}^{2} \mathrm{P}_{3 / 2}$ & 49460.6 & ${ }^{2} \mathrm{P}_{3 / 2}-{ }^{2} \mathrm{D}_{3 / 2}^{0}$ & 2627.91 & & & & $\mathrm{vw}$ & \\
\hline $7 \mathrm{~s}+\mathrm{P}_{5 / 2}$ & 48489.6 & ${ }^{4} \mathrm{P}_{5 / 2}-{ }^{2} \mathrm{D}_{5 / 2}^{0}$ & 3024.64 & & & w & w & $\mathrm{m}$ \\
\hline $8 s{ }^{4} \mathrm{P}_{1 / 2}$ & 47373.2 & ${ }^{4} \mathrm{P}_{1 / 2}-{ }^{2} \mathrm{D}_{3 / 2}^{0}$ & $2780.52^{\mathrm{d}}$ & & & & & w \\
\hline \multirow[t]{3}{*}{$7 \mathrm{~s} \cdot 2 \mathrm{P}_{1 / 2}$} & 45916.0 & ${ }^{2} \mathrm{P}_{1 / 2}-{ }^{4} \mathrm{~S}_{3 / 2}^{0}$ & 2176.62 & $\mathrm{vW}$ & & & & \\
\hline & & ${ }^{2} \mathrm{P}_{1 / 2}-{ }^{2} \mathrm{D}_{3 / 2}^{0}$ & 2897.98 & $\mathrm{vW}$ & & $\mathrm{m}$ & w & $\mathrm{m}$ \\
\hline & & ${ }^{2} \mathrm{P}_{1 / 2}-{ }^{2} \mathrm{P}_{1 / 2}^{0}$ & 4121.53 & & & & & s \\
\hline \multirow[t]{3}{*}{$7 \mathrm{~s}{ }^{4} \mathrm{P}_{3 / 2}$} & 44865.3 & ${ }^{4} \mathrm{P}_{3 / 2}-{ }^{4} \mathrm{~S}_{3 / 2}^{0}$ & $2228.25^{e}$ & $\mathrm{vW}$ & & & & \\
\hline & & ${ }^{4} \mathrm{P}_{3 / 2}-{ }^{2} \mathrm{D}_{3 / 2}^{0}$ & $2989.03^{f}$ & vw & & $\mathrm{m}$ & w & $\mathrm{m}$ \\
\hline & & ${ }^{4} \mathrm{P}_{3 / 2}-{ }^{2} \mathrm{D}_{5 / 2}^{0}$ & 3397.21 & & & $\mathrm{~m}$ & $\mathrm{~m}$ & s \\
\hline \multirow[t]{2}{*}{$6 \mathrm{~d}-\mathrm{D}_{5 / 2}$} & 44817.1 & ${ }^{2} \mathrm{D}_{5 / 2}-{ }^{4} \mathrm{~S}_{3 / 2}^{0}$ & $2230.61^{e}$ & vw & & & & \\
\hline & & ${ }^{2} \mathrm{D}_{5 / 2}-{ }^{2} \mathrm{D}_{3 / 2}^{0}$ & $2993.34^{f}$ & $\mathrm{vw}$ & & $\mathrm{m}$ & w & $\mathrm{m}$ \\
\hline \multirow[t]{2}{*}{$7 \mathrm{~s}{ }^{4} \mathrm{P}_{1 / 2}$} & 32588.0 & ${ }^{4} \mathrm{P}_{1 / 2}-{ }^{4} \mathrm{~S}_{3 / 2}^{0}$ & 3067.72 & $\mathrm{vW}$ & $\mathrm{m}$ & $\mathrm{m}$ & $\mathrm{m}$ & s \\
\hline & & ${ }^{4} \mathrm{P}_{1 / 2}-{ }^{2} \mathrm{D}_{3 / 2}^{0}$ & 4722.55 & & vs & vs & vs & vs \\
\hline
\end{tabular}

a Levels measured by Joshi and Srivastava (Ref. 4).

b Values given by A. N. Saidel et al., H. F. Clearman or S. Mrozowski (Ref. 5).

c Both transitions correspond to the same wavelength, and it was not possible to know which one is involved.

d. e. $f$ The resolution of the monochromator used was not sufficient to determine if either or both of these two lines are excited.

g vs: very strong: s: strong: m: mean: w: weak: vw: very weak. 


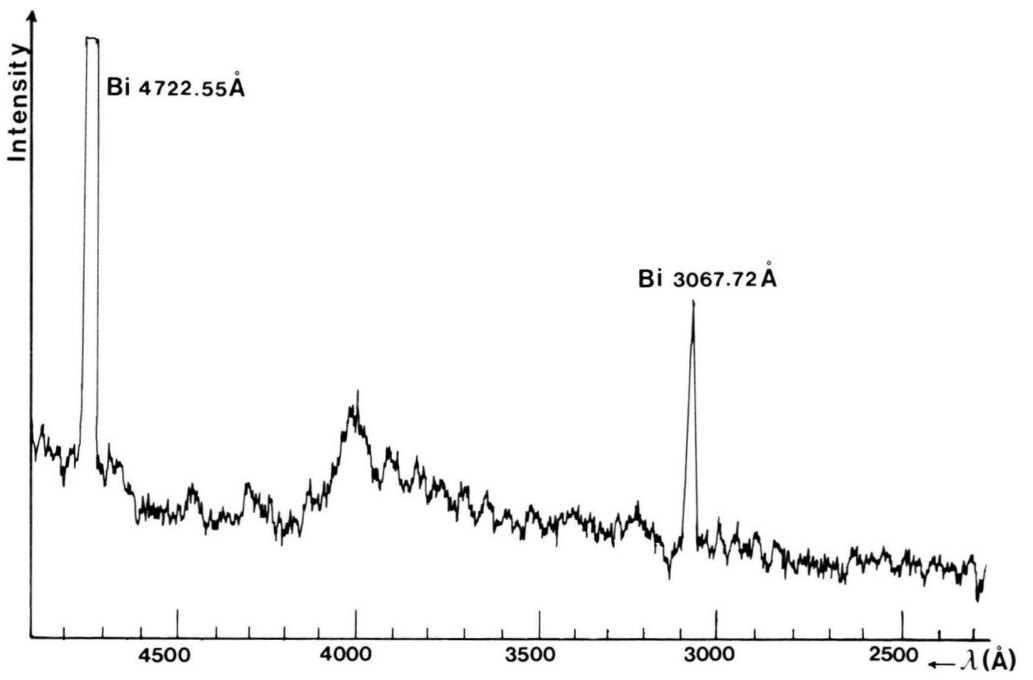

Fig. 1. Part of fluorescence spectrum of bismuth upon pure visible excitation $(532 \mathrm{~nm})$.

The visible light $(532 \mathrm{~nm})$ gives rise to a weak molecular structure at roughly $400 \mathrm{~nm}$ (Fig. 1). Its origin may be explained in the following manner: a first photon raises a bismuth molecule to state A (see Figure 2). The absorption of a second photon excites the latter to a new state of even parity, called $W_{\mathrm{g}}$, which radiates to the low-lying odd state $B_{\mathrm{u}} . W_{\mathrm{g}}$ is thus situated at least at $37600 \mathrm{~cm}^{-1}$ from the ground state $X_{\mathrm{g}}$. When both infrared and visible laser

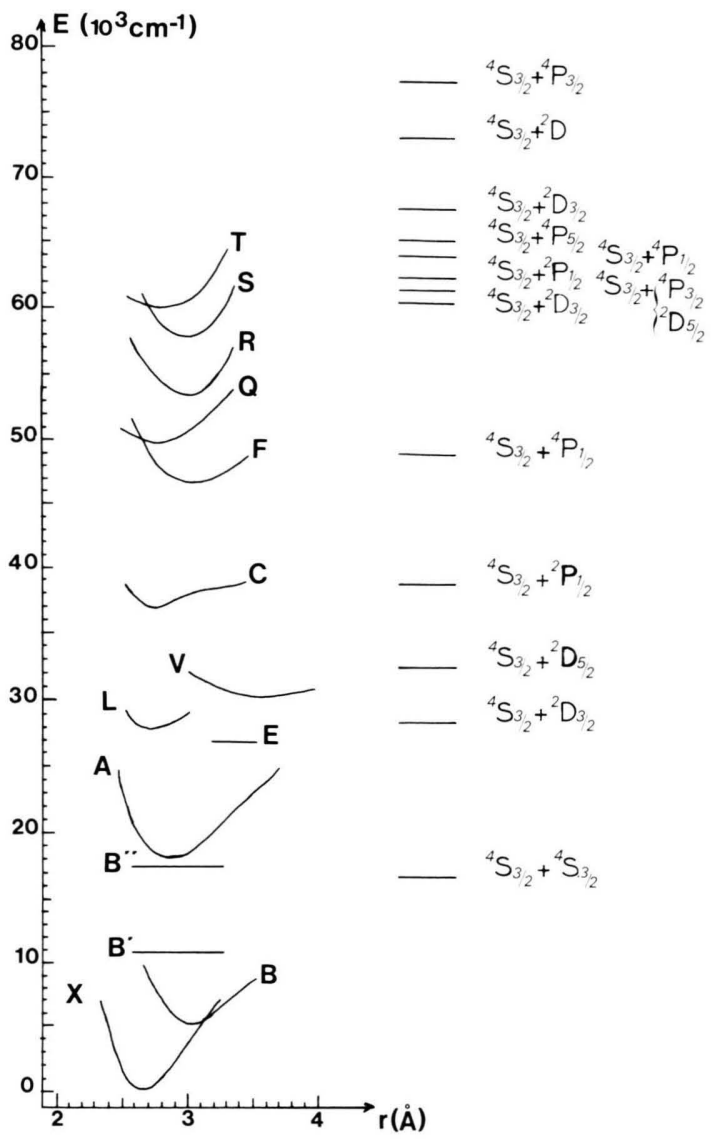

Fig. 2. Potential energy curves for the best observed states of $\mathrm{Bi}_{2}$ (after ref. 2). radiations enter the vapour zone, another molecular structure appears at $250 \mathrm{~nm}$ approximately. It is due to the further absorption of an infrared photon by a molecule in the $W_{\mathrm{g}}$ state. The final state attained in this manner is of odd parity, and lies at more than $47000 \mathrm{~cm}^{-1}$ from the $X$ state. It may be one of the already known $F$ or $Q$ states (see Fig. 2), or a new one. The molecular emission observed at $250 \mathrm{~nm}$ is due to a transition towards the lowlying even states $X$ or $B^{\prime}$.

Atomic lines have been observed in any case of excitation (see Table 1). At least two photons are absorbed by a bismuth molecule which is thus excited to a repulsive state [3]. The subsequent dissociation yields an atom in the ground state $\left({ }^{4} S_{3 / 2}\right)$ and an excited atom, which gives rise to the atomic emission. The lines observed upon absorption of infrared photons are comparatively very weak, because at least 6 photons are involved. $7 \mathrm{~s}^{4} \mathrm{P}_{1 / 2}$ is the first excited level populated, and the lines originating from it ( $3067.72 \AA$ and $4722.55 \AA$ ) are the strongest ones. 3 visible or 2 ultraviolet photons are absorbed in the process leading to this level. The other levels are not populated by visible photons alone. One further infrared photon must be absorbed (after 3 visible or $2 \mathrm{U}$. V. photons) in order to yield the $6 \mathrm{~d}^{2} \mathrm{D}_{5 / 2}, 7 \mathrm{~s}{ }^{4} \mathrm{P}_{3 / 2}, 7 \mathrm{~s}^{2} \mathrm{P}_{1 / 2}$ and $7 \mathrm{~s}{ }^{4} \mathrm{P}_{5 / 2}$ levels, whereas the $8 \mathrm{~s}{ }^{4} \mathrm{P}_{1 / 2}$ level is excited only in the presence of both visible and $\mathrm{U}$.V. radiations (2 photons from the former and one photon from the latter are required).

To sum up, two new molecular emissions have been observed in bismuth. They originate from a new bound state $W$ of even parity, lying at more than $37600 \mathrm{~cm}^{-1}$, and another one of odd symmetry, having an energy greater than $47000 \mathrm{~cm}^{-1}$. Besides, several even or odd repulsive states lie at more than $50000 \mathrm{~cm}^{-1}$ and are optically connected to the ground state. By multiphoton absorption they yield ground and excited atoms of different energies, the latter giving rise to several known emission lines.

The molecular fluorescence is rather weak in the type of excitation used. A dye laser would be better suited to reach higher intensities; otherwise, no laser action can be expected.

The authors are indebted to Prof. Jean d'Incan for his interest in this work and many helpful discussions. 
[1] W. P. West and H. P. Broida, Chem. Phys. Lett. 56, 283 (1978); B. Wellegehausen, D. Friede, and G. Steger, Opt. Commun. 26, 391 (1978); S. Drosch and G. Gerber, J. Chem. Phys. 77, 123 (1982).

[2] G. Gerber, K. Sakurai, and H. P. Broida, J. Chem. Phys. 64, 3410 (1976); - G. Gerber and H. P. Broida, Ibid. 64, 3423 (1976); - N. Damany, J. Figuet, and A. Topouzkhanian, Chem. Phys. 63, 157 (1981); G. Gerber, H. Hönninger, and J. Janes, Chem. Phys. Lett. 85, 415 (1982); - G. Ehret and G. Gerber, Chem. Phys. 66, 27 (1982); - C. Effantin, A. Topouzkhanian, J. Figuet, J. D'Incan, R. F. Barrow, and J. Vergès, J. Phys. B 15, 3829 (1982) and references therein.
[3] W. A. Young, M. Y. Mirza, and W. W. Duley, J. Phys. B 13, 3175 (1980) and references therein.

[4] Y. N. Joshi and R. P. Srivastava, Can. J. Phys. 56, 1157 (1978).

[5] A. N. Saidel, W. K. Prokofjew, and S. M. Raiski, Tables of Spectrum Lines, VEB Verlag Technik, Berlin 1961: H. E. Clearman, J. Opt. Soc. Amer. 42, 373 (1952); S. Mrozowski, Phys. Rev. 62, 526 (1942). 